\title{
STUDIES ON PERIPLANETA AMERICANA
}

\section{SELECTION FOR HETEROZYGOSITY}

B. JOHN

Zoology Department, University College of South Wales and

Monmouthshire, Cardiff

and

K. R. LEWIS

Botany Department, University of Oxford

\section{INTRODUCTION}

Received 6.vii.57

IN an earlier account we described the occurrence of interchange heterozygosity in a wild isolated population of the American cockroach from a coal mine in Treharris, Glamorgan and in a laboratory culture established from this population. As a result of these investigations it was suggested that the wild population included two mating groups (Lewis and John, 1957).

The present account arises from an extended investigation of the Treharris population which supports this suggestion. It also deals with an analysis of material from seven other sources, two wild populations and five laboratory cultures. The details of these populations are given in table $I$ and we are indebted to the persons mentioned there for supplying material.

Interchanges do not arise very often and the individuals in which they originate are always heterozygous for the change. In the absence of selection, inbreeding is expected to reduce the frequency of heterozygotes. Therefore, the high frequency of interchange heterozygotes in these cockroach populations, all of which are inbred, must indicate that the structural hybrids are at a selective advantage. Selection for genic heterozygosity is revealed by interchange hybridity (Darlington and La Cour, I950).

The chromosome number of $P$. americana is $33 \delta^{*}$ and 34 ㅇ. All the analyses were made on adult male imagines and as the $\mathrm{X}$ chromosome is not involved in any of the interchanges it has been omitted in the tabulation of data. The cytological methods have been described elsewhere (John and Lewis, 1957).

\section{THE INCIDENCE OF INTERCHANGE HETEROZYGOTES}

In addition to structural homozygotes, individuals heterozygous for one, two and three interchanges have been found. (plate, figs. 4-9). The distribution of the various karyotypes in the ten localities studied is given in table 2. A $\chi^{2}$ test showed no significant difference between the wild population and the laboratory culture totals when all classes were considered (table 3). But when the ratio of homozygotes to heterozygotes was tested the frequency of homozygotes was found to 
TABLE I

Sources of material

\begin{tabular}{|c|c|c|c|c|c|}
\hline \multicolumn{4}{|c|}{ Population } & Prefix & Origin and remarks \\
\hline (a) & $\begin{array}{l}\text { Wild } \\
\text { Tonypandy } \\
\text { Cilfynydd } \\
\text { Treharris, lo } \\
\text { Treharris, lo }\end{array}$ & $\begin{array}{l}\text { cation } \\
\text { cation }\end{array}$ & $\begin{array}{l}1 \\
2\end{array}$ & $\begin{array}{c}\mathrm{C} \\
\mathrm{T}_{1} \\
\mathrm{~T}_{2}\end{array}$ & $\begin{array}{l}\text { Anthony and Pandy Colliery, Glamorgan; } \\
\text { sunk in } 1875 \\
\text { Cilfynydd Colliery, Glamorgan; sunk in } \\
\text { I } 888 \\
\text { Two distinct breeding units from the Deep } \\
\text { Navigation Colliery, Treharris, Glamorgan; } \\
\text { sunk in } 1873\end{array}$ \\
\hline (b) & $\begin{array}{l}\text { Culture } \\
\text { Treharris cu } \\
\text { Manchester }\end{array}$ & lture & - & $\begin{array}{l}\text { TC } \\
\text { M }\end{array}$ & $\begin{array}{l}\text { Culture established from Treharris mine (T I } \\
\text { and T } 2 \text { mixed) in } 1946 \\
\text { Culture established from individuals collected } \\
\text { at Manchester Zoo, subsequently mixed } \\
\text { with material from Biological Supply } \\
\text { Agencies. Donor, Prof. R. G. Dennel, } \\
\text { Dept. Zoology, Manchester Univ. } \\
\text { Sub-cultured from Manchester population, no } \\
\text { subsequent mixing. Donor, Prof. A. D. } \\
\text { Peacock, Dept. Natural History, Univ. of } \\
\text { St Andrews } \\
\text { Origin not known. Donor, Dr A. G. Hamilton, } \\
\text { Dept. Biology, St Thomas Hospital Medical } \\
\text { School } \\
\text { Sub-cultured from London population, no } \\
\text { subsequent mixing. Donor, Dr I. M. } \\
\text { Crichton, Dept. Zoology, Reading Univ. } \\
\text { Origin not known. Donor, Miss E. S. Bartlett, } \\
\text { Min. Agric. and Fish., Surbiton }\end{array}$ \\
\hline
\end{tabular}

TABLE 2

Incidence of interchange heterozygotes in ten populations of P. americana

\begin{tabular}{|c|c|c|c|c|c|c|}
\hline \multirow{2}{*}{ Locality } & \multicolumn{5}{|c|}{ Classes } & \multirow{2}{*}{$\begin{array}{c}\text { Total } \\
\text { individuals }\end{array}$} \\
\hline & I6 II & $\begin{array}{l}\text { I4 II }+ \\
\text { I IV }\end{array}$ & $\begin{array}{l}12 \mathrm{II}+ \\
2 \mathrm{IV}\end{array}$ & $\begin{array}{l}13 \mathrm{II+}+ \\
\text { I VI }\end{array}$ & $\begin{array}{c}\text { II II }+1 \mathrm{VI}+ \\
\text { I IV }\end{array}$ & \\
\hline $\begin{array}{l}\text { (a) Wild } \\
\mathrm{P} \\
\mathrm{C} \\
\mathrm{T}_{\mathrm{I}} \\
\mathrm{T}_{2}\end{array}$ & $\begin{array}{r}4 \\
5 \\
12 \\
12\end{array}$ & $\begin{array}{r}4 \\
8 \\
16 \\
22\end{array}$ & $\begin{array}{r}2 \\
\text { I } \\
\text { IO } \\
9\end{array}$ & $\begin{array}{r}\mathrm{I} \\
\mathrm{I} \\
7 \\
\ldots\end{array}$ & $\begin{array}{r}\cdots \\
\ldots \\
5 \\
\ldots\end{array}$ & $\begin{array}{l}\text { I I } \\
\text { I } 5 \\
50 \\
43\end{array}$ \\
\hline $\begin{array}{l}\text { (b) Culture } \\
\text { TC } \\
\text { M } \\
\text { D } \\
\text { L } \\
\text { R } \\
\text { S }\end{array}$ & $\begin{array}{r}10 \\
3 \\
1 \\
\ldots \\
5 \\
1\end{array}$ & $\begin{array}{r}21 \\
8 \\
6 \\
5 \\
7 \\
5\end{array}$ & $\begin{array}{r}\text { I } 2 \\
3 \\
5 \\
1 \\
3 \\
4\end{array}$ & $\begin{array}{r}1 \\
3 \\
\ldots \\
2 \\
\ldots \\
\ldots\end{array}$ & $\begin{array}{r}6 \\
3 \\
2 \\
1 \\
\ldots \\
\end{array}$ & $\begin{array}{r}50 \\
20 \\
14 \\
9 \\
15 \\
11\end{array}$ \\
\hline
\end{tabular}


be higher in nature than in culture (table 4). Furthermore, the average number of interchanges per individual (i.e. the coefficient of

TABLE 3

The contingency table for the distribution of karyotypes in wild and laboratory populations

\begin{tabular}{|c|c|c|c|c|c|c|c|}
\hline \multirow{2}{*}{ Locality } & & \multicolumn{5}{|c|}{ Classes } & \multirow{2}{*}{$\begin{array}{c}\text { Total } \\
\text { individuals }\end{array}$} \\
\hline & & II & I IV & 2 IV & I VI & $\begin{array}{l}\text { I I + } \\
1 \text { IV }\end{array}$ & \\
\hline Wild . & . & 33 & $5^{\circ}$ & 22 & 9 & 5 & II \\
\hline Culture. & - & 20 & 52 & 28 & 6 & 13 & II 9 \\
\hline Totals & - & 53 & 102 & 50 & 15 & 18 & $23^{8}$ \\
\hline
\end{tabular}

$x_{[4]}^{2}=8 \cdot \mathbf{I} \quad \mathbf{P}=0.05-0 \cdot \mathbf{I}$

TABLE 4

The contingency table for the distribution of homozygotes and heterozygotes in wild and laboratory populations

\begin{tabular}{|c|c|c|c|c|}
\hline \multirow{2}{*}{ Locality } & & \multicolumn{2}{|c|}{ Classes } & \multirow{2}{*}{$\begin{array}{c}\text { Total } \\
\text { individuals }\end{array}$} \\
\hline & & Homozygotes & Heterozygotes & \\
\hline Wild & . & 33 & 86 & I 19 \\
\hline \multirow[t]{2}{*}{ Culture } & . & 20 & 99 & II \\
\hline & . & 53 & 185 & 238 \\
\hline
\end{tabular}

$$
x_{[\mathrm{r}]}^{2}=4 \cdot 1 \quad \mathrm{P}=0.02-0.05
$$

TABLE 5

Comparison of the coefficient of interchange heterozygosity in wild and laboratory populations

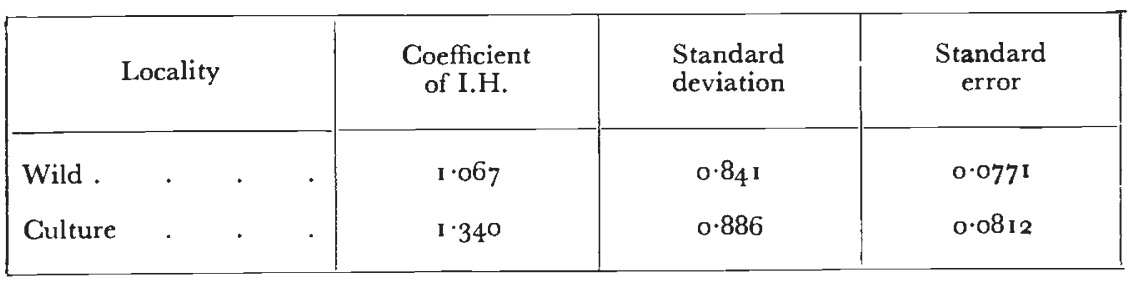

$$
\frac{\vec{d}}{s_{d[237]}}=\frac{0.273}{0.112}=2.4 \quad P=0.01-0.02
$$

interchange heterozygosity) is higher in laboratory cultures than in nature, the variance in both being approximately the same (table 5). 
The distribution of individuals with different degrees of heterozygosity is shown in text-fig. I.

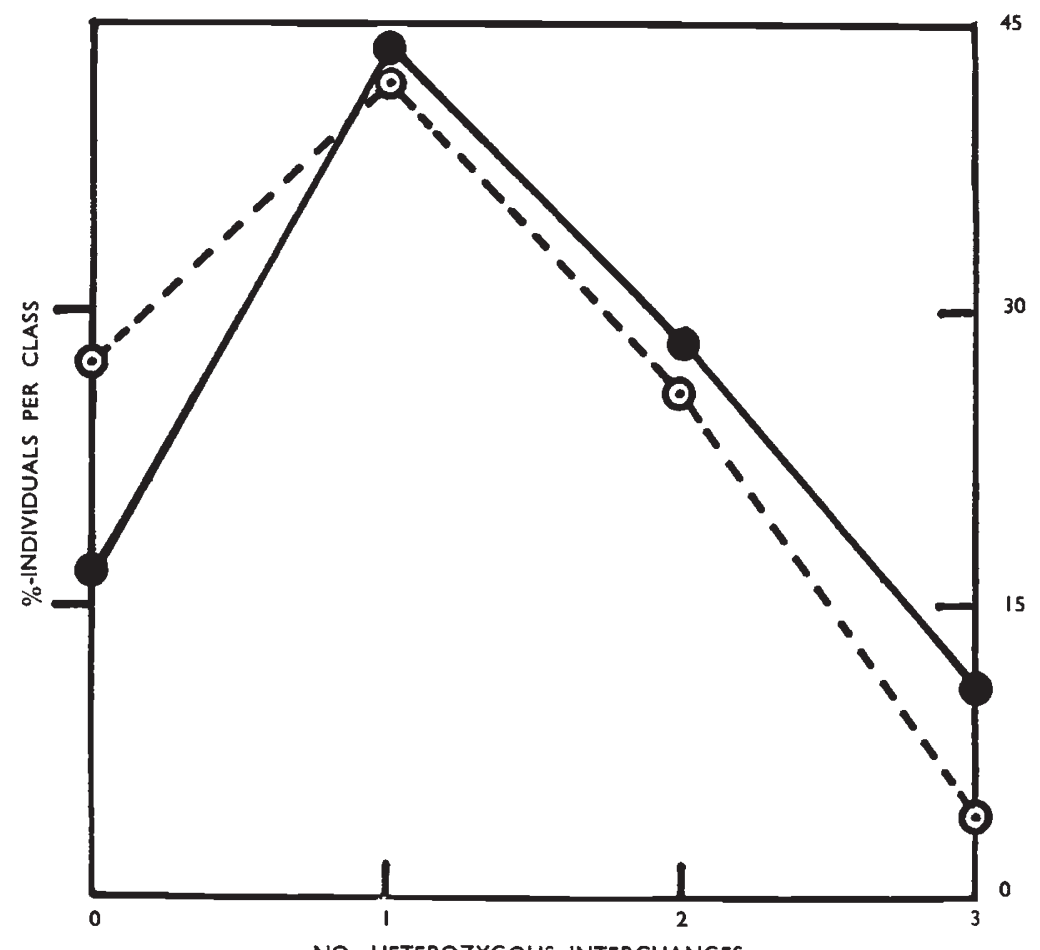

NO. HETEROZYGOUS INTERCHANGES

TExT-FIG. I.-Frequency of individuals with different levels of heterozygosity in wild $(\ldots)$ and laboratory (_- ) populations of $P$. americana.

TABLE 6

The degree of maximum multiple formation

\begin{tabular}{|c|c|c|c|c|c|c|c|c|c|c|}
\hline \multirow{3}{*}{ Karyotype } & \multicolumn{8}{|c|}{ Per cent. maximum multiple formation } & \multirow{3}{*}{$\begin{array}{c}\text { Total } \\
\text { individuals }\end{array}$} & \multirow{3}{*}{$\begin{array}{l}\text { Tota } \\
\text { cells }\end{array}$} \\
\hline & \multicolumn{8}{|c|}{ No. of individuals observed per class } & & \\
\hline & $21-30$ & $3 I-40$ & $4^{1-50}$ & $5^{1-6 o}$ & $61-70$ & $7 \mathrm{I}-80$ & $8 \mathrm{I}-90$ & $9^{1-I 0 O}$ & & \\
\hline I IV & $\ldots$ & 2 & $\ldots$ & 2 & 3 & I 4 & I 5 & 24 & $6 o$ & I 86 \\
\hline 2 IV & 2 & I & I & $\ldots$ & 2 & 10 & 7 & 7 & 30 & 964 \\
\hline I VI & $\ldots$ & $\ldots$ & $\ldots$ & $\ldots$ & $\ldots$ & $\ldots$ & I & I I & 12 & $43^{1}$ \\
\hline $\mathrm{I} \mathrm{VI}+\mathrm{I} \mathrm{IV}$ & $\ldots$ & $\ldots$ & $\ldots$ & $\ldots$ & $\ldots$ & I & 3 & 6 & Io & 410 \\
\hline
\end{tabular}

\section{FERTILITY}

Fertility will depend in part on both the frequency of multiple formation and the orientation of the multiples. The degree of maximum multiple formation is high for all karyotypes (table 6). 
As expected, it is lower in individuals heterozygous for two independent interchanges but, contrary to expectation, the ring-of-six heterozygotes appear to have the most regular pairing. Nine out of twelve of these heterozygotes showed roo per cent. maximum multiple formation. We can suggest no reason for this.

TABLE 7

The occurrence of univalents

\begin{tabular}{|c|c|c|c|c|c|}
\hline $\begin{array}{l}\text { Individual } \\
\text { no. }\end{array}$ & Type & $\begin{array}{l}\text { Total } \\
\text { cells }\end{array}$ & Univalent type & $\begin{array}{c}\text { Times } \\
\text { observed }\end{array}$ & Cause \\
\hline \multirow[t]{2}{*}{ TC-II } & \multirow[t]{2}{*}{2 IV } & \multirow[t]{2}{*}{$4^{\circ}$} & $\mathrm{R} I V+\mathrm{C} I I I+\mathrm{I} 2 \mathrm{II}+\mathrm{I} I$ & 1 & \multirow{3}{*}{$\begin{array}{l}\text { Failure of interchange } \\
\text { chromosomes }\end{array}$} \\
\hline & & & $\mathrm{CIV}+\mathrm{I}_{3} \mathrm{II}+2 \mathrm{I}$ & I & \\
\hline \multirow{2}{*}{$\begin{array}{ll}\mathrm{D}-6 & \\
& \circ\end{array}$} & \multirow[t]{2}{*}{$2 \mathrm{IV}$} & \multirow[t]{2}{*}{ I 2} & $\mathrm{R} I V+\mathrm{I}_{3} \mathrm{II}+2 \mathrm{I}$ & I & \\
\hline & & & $2 I V+1 I I I+2 I$ & 4 & \multirow[t]{2}{*}{ Autosomal failure } \\
\hline D-8 & I6 II & Io & ${ }_{15} I I+2 I$ & I & \\
\hline
\end{tabular}

Univalents and numerically uneven multiples which would reduce fertility rarely occur. In addition to the individuals described in table 7 , two univalent $\mathrm{X}$ chromosomes were observed in twenty-six cells of one individual (D-II) which were at the first division of meiosis.

TABLE 8

Frequency of disjunctional orientation of associations of four

\begin{tabular}{|c|c|c|c|c|c|c|}
\hline \multirow{3}{*}{ Orientation } & \multicolumn{4}{|c|}{ Karyotype } & \multirow{3}{*}{ Total } & \multirow{3}{*}{$\begin{array}{c}\text { Frequency } \\
\text { of } \\
\text { disjunction }\end{array}$} \\
\hline & \multicolumn{2}{|c|}{ I IV } & \multicolumn{2}{|c|}{$2 \mathrm{IV}$} & & \\
\hline & Rings & Chains & Rings & Chains & & \\
\hline \multirow{2}{*}{$\begin{array}{l}\text { Disjunctional } \\
\text { Non-disjunctional }\end{array}$} & 49 & I & 35 & $3^{\mathrm{r}}$ & 116 & \multirow{2}{*}{$0.9^{2}$} \\
\hline & 8 & $\ldots$ & 2 & $\ldots$ & 10 & \\
\hline Total cells & \multicolumn{2}{|c|}{$5^{8}$} & \multicolumn{2}{|c|}{$4^{6}$} & & \\
\hline
\end{tabular}

Normal chromosome counts were obtained at second division and at mitosis. The aberration, therefore, was not systematic and probably arose by non-disjunction of the $\mathrm{X}$ chromosome at a mitosis preceding meiosis by at least five divisions. As in normal cells, the $\mathrm{X}$ chromosomes were positively heterochromatic and, due to this precocity, they did not pair ( $c f$. Makino, I 939 ; Suomalainen, 1946).

The frequency of disjunction also is high (table 8). For example, 
in TC-3, heterozygous for a single interchange, the ring was disjunctional in 0.8 of the cases and in TG-II, heterozygous for two independent interchanges, the multiples in seventeen cells were invariably disjunctional. An association of six has been observed at metaphase in only seven cells but was disjunctional in all of them (text-fig. 2).

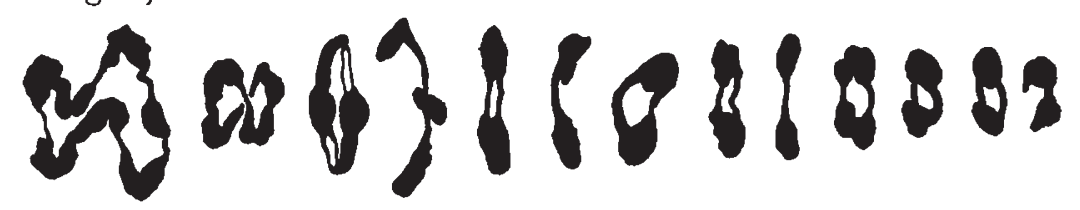

TEXT-FIG. 2.-Orientated pro-metaphase with one disjunctional ring-of-six and one disjunctional ring-of-four to the extreme left, $X$ to extreme right. Chromosomes aligned for clarity (TC-7, $a$-bromonaphthalene I hr. $\times$ I 800 ).

\section{THE TREHARRIS POPULATION}

Our earlier investigation did not reveal the presence of multiple associations higher than four in the wild population from Treharris although they occurred in the laboratory culture. This can now be attributed to sampling error, a possibility we did not exclude. Ringof-six heterozygotes have been found in T I but not, as yet, in T 2. A $\chi^{2}$ test for heterogeneity showed that the populations in these two localities were significantly different (table 9).

TABLE 9

The contingency table for the distribution of karyotypes in $T_{I}$ and $T_{2}$

\begin{tabular}{|c|c|c|c|c|c|c|}
\hline \multirow{2}{*}{ Locality } & \multicolumn{5}{|c|}{ Classes } & \multirow{2}{*}{$\begin{array}{c}\text { Total } \\
\text { individuals }\end{array}$} \\
\hline & II & I IV & 2 IV & I VI & I VI+IIV & \\
\hline $\mathrm{T}_{\mathrm{I}}$ & I 2 & I 6 & IO & 7 & 5 & $5^{\circ}$ \\
\hline $\mathrm{T}_{2}$ & I 2 & 22 & 9 & $\ldots$ & $\cdots$ & 43 \\
\hline Totals & 24 & $3^{8}$ & I 9 & 7 & 5 & 93 \\
\hline
\end{tabular}

At pachytene in $P$. americana the centromere often appears as a constriction and repulsion is localised between homologous centromeres (plate, fig. 5). This makes it possible to determine the point of interchange and, in all cases, this has occurred at or near the centromere. Pachytene associations in many cases can be distinguished by the lengths and arrangement of their arms.

\section{(i) Associations of four}

Four morphologically distinguishable cross associations have been observed.

Type I.-with four long arms of approximately equal length (plate, fig. I, Lewis and John, I957; text-fig. $3^{a}$ ). 
Type 2.-with a long, two medium and a short arm in that order (plate, fig. 1 , text-fig. $3^{b}$ ).

Type 3.-with a long, two medium and a medium-short arm in that order (plate, fig. 2, text-fig. $3 c$ ).

Type 4.-with two long, a medium and a short arm (plate, fig. 3 , text-fig. $3^{d}$ ).

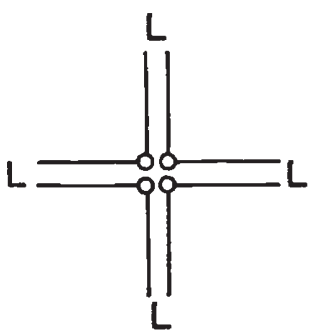

(a)

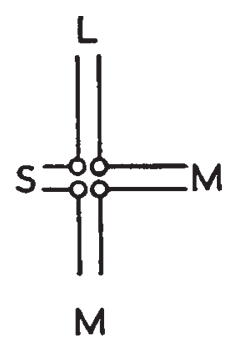

(b)

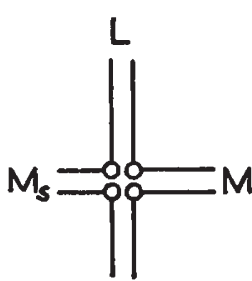

M

(c)

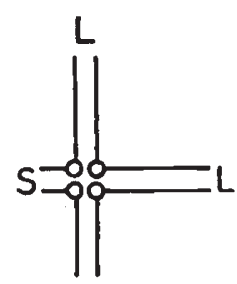

M

(d)

TEXT-FIG. 3.-Diagrammatic representation of the morphologically distinguishable pachytene associations of four.
(a) IV Type I (cf. plate, fig. 1, Lewis and John, 1957)
(b) IV Type 2 ( $c f$. plate, fig. I)
(c) IV Type 3 (cf. plate, fig. 2)
(d) IV Type 4 (cf. plate, fig. 3 ).

\section{(ii) Associations of six}

Three morphologically distinguishable associations of six have been observed so far. In all cases the pachytene associations are approximately star-shaped indicating short differential segments. Also, all three association types consist of two long, two medium, one medium-short and one short arm. The arrangement of the arms in the three types is as follows :-

Type I.-with the arm sequence: long, medium, long, mediumshort, medium, short (text-fig. 4a).

Type 2.-where the arms are arranged long, medium-short, long, medium, short, medium (text-fig. $4 b$ ), and

Type 3.-with the arms in the following order: long, long, medium, medium-short, medium, short (text-fig. $4 c$ ).

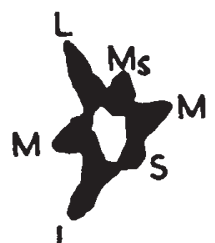

(a)

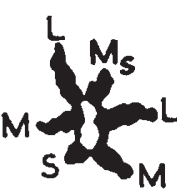

(b)

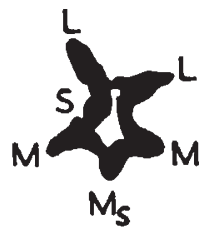

(c)

TEXT-FIG. 4.-Types of morphologically distinguishable pachytene associations of six. $(\times 1250)$.

(a) VI Type I ( $c f$. plate, fig. 6, Lewis and John, 1957)

(b) VI Type 2 (cf. text.fig. 5)

(c) VI Type 3 . 
The following observations are also relevant to the explanation which we advance in the next section to account for these configurations :

(i) Ring IV Type 3 and Ring VI Type 2 have been found in the same individual (text-fig. 5).

(ii) Karyotypes heterozygous for three independent interchanges were recorded in our earlier investigation.

(iii) Rings higher than six have never been observed, and

(iv) Individuals with two rings-of-six have not been found although in all, over two hundred and fifty individuals have been examined.

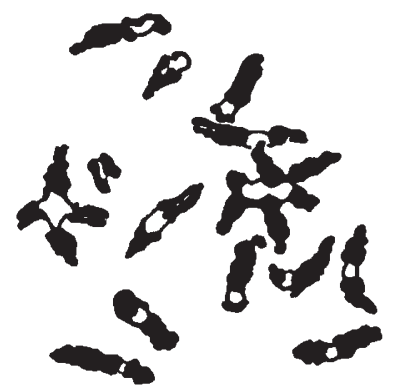

TeXT-FIG. 5.-Pachytene with an association of six (Type 2) and an association of four

(Type 3 ). Centromeric regions forming clear gaps ( $\mathrm{T}_{1-42}$, colchicine $2 \frac{1}{2} \mathrm{hr} . \quad \times 125^{\mathrm{O}}$.)

\section{(iii) The interchanges}

The number of interchanges necessary to account for the above configurations is decreased if the rings-of-six can give rise to rings-of-

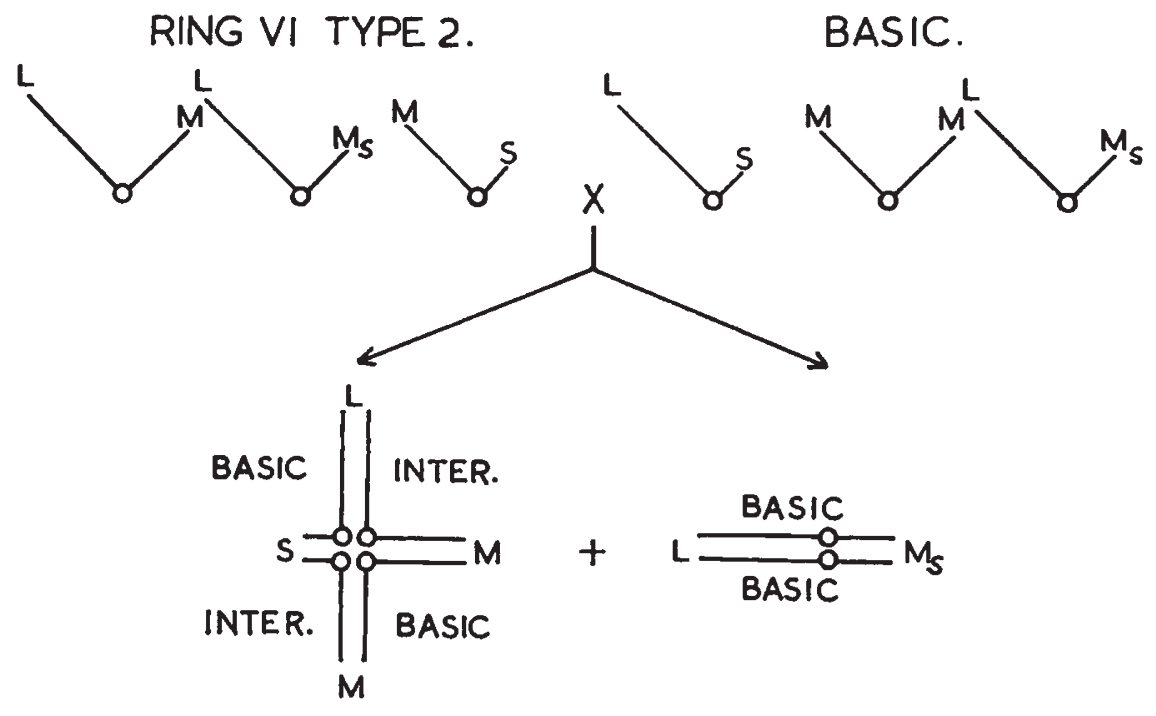

RING IV TYPE 2.

TexT-FIG. 6.-Derivation of Ring IV Type 2 by crossing Ring VI Type 2 with a basic homozygote. 
four when crossed with the basic karyotype. Ring VI Type 2 gives two types of gamete both with (Long: Medium), (Long: Mediumshort), and (Medium : Short) chromosomes. This heterozygote can give the Ring IV Type 2 configuration if the basic chromosomes are $(\mathrm{L}: \mathrm{S}),(\mathrm{M}: \mathrm{M}),(\mathrm{L}: \mathrm{Ms})$ as shown in text-fig. 6.

In the same way the Ring VI Type 3 configuration can give the Ring IV Type 3 configuration but again only if the basic chromosomes are $(\mathrm{L}: \mathrm{S}),(\mathbf{M}: \mathrm{M}),(\mathrm{L}: \mathrm{Ms})$.

This, together with observations (iii) and (iv) above, have led us to conclude that all the rings-of-six involve the same chromosomes. The apparent absence of individuals heterozygous for more than four interchanges may be because they exceed the hybridity optimum (Darlington and La Cour, 1950). But the coincidence of arm lengths in the observed heterozygotes has led us to the following scheme :

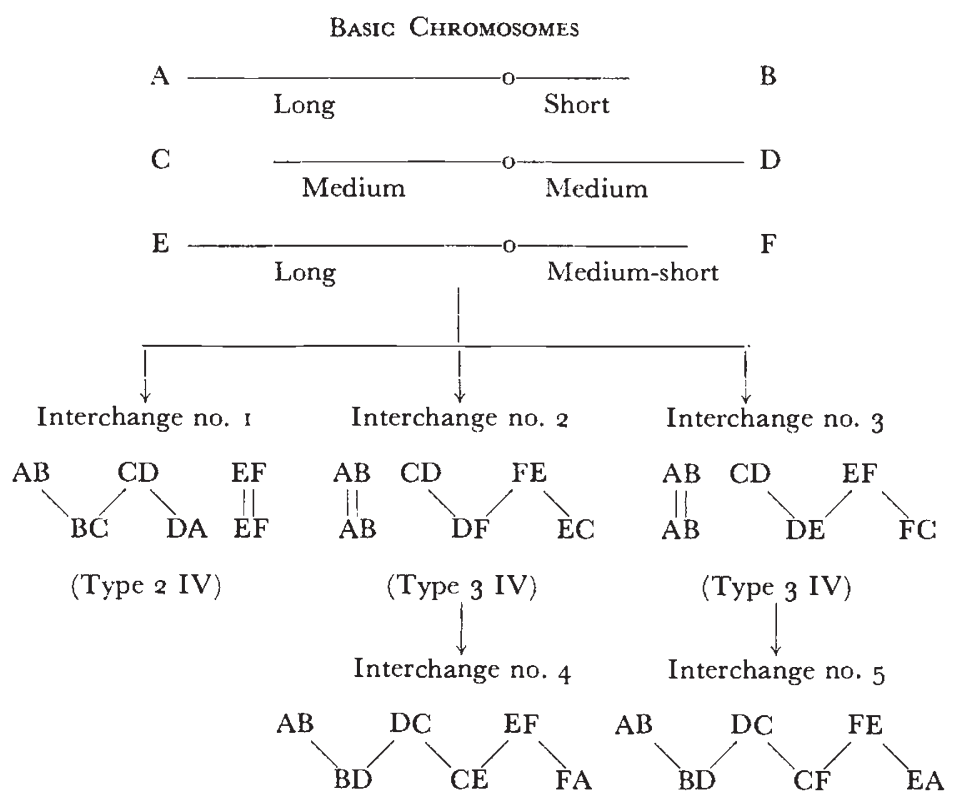

The Ring VI Type I can then be obtained by crossing interchange heterozygotes $\mathrm{I}$ and 3 , Ring VI Type 2 by crossing interchanges $I$ and 4 ,

Ring VI Type 3 by crossing interchanges 2 and 5 , and

Ring IV Type 4 by crossing interchanges 3 and 5 .

If this peirastic scheme is correct, the various types of configurations, both of four and of six, are mutually exclusive. It would follow, therefore, that the rings-of-four in the VI +IV individuals must be due to other, independent, interchanges : interchanges of two kinds.

Firstly, an interchange (No. 6) involving isobrachial chromosomes to give the Ring IV Type I which cannot be derived from any of the rings-of-six. Secondly, an interchange (No. 7) giving a pachytene association of four morphologically similar to the Ring IV Type 3. This is necessary because such a multiple has been found together 
with a ring-of-six in the same individual (text-fig. 5). That two morphologically similar associations of Ring IV Type 3 do occur is shown by their occurrence in the same cell, albeit in an individual from another population (C-I).

This explanation on the basis of seven interchanges satisfies all the conditions (i)-(iv) above. However, it also makes possible the formation of pachytene associations of a kind not yet observed. Since analyses of pachytene can be made only infrequently this is not surprising. A more serious objection is that it makes possible the formation of rings-of-six in the $\mathrm{T} 2$ population.

The recorded distribution of morphologically distinguishable interchange associations is given in table Io. To account for this distribution, T 2 need have only interchanges Nos. I, 3 and 5 while interchange No. 3 may be absent from T 1. However, we do not regard these findings complete. Ring VI Type I, for example, is expected to occur in $\mathrm{T}_{2}$ although no rings-of-six have so far been recorded in this population.

TABLE IO

Distribution of morphologically distinguishable interchanges in nine populations of $\mathrm{P}$. americana

\begin{tabular}{|c|c|c|c|c|c|c|c|}
\hline \multirow{2}{*}{ Locality } & \multicolumn{4}{|c|}{ IV } & \multicolumn{3}{|c|}{ VI } \\
\hline & Type I & Type 2 & Type 3 & Type 4 & Type I & Type 2 & Type 3 \\
\hline$T_{I}$ & + & + & + & $\ldots$ & $\ldots$ & + & + \\
\hline $\mathrm{T} 2$ & $\cdots$ & + & + & + & $\cdots$ & $\cdots$ & $\ldots$ \\
\hline $\mathrm{T} \mathrm{C}$ & + & + & + & + & + & $\cdots$ & $\ldots$ \\
\hline $\mathrm{P}$ & $\ldots$ & $\ldots$ & + & $\ldots$ & $\ldots$ & $\cdots$ & $\ldots$ \\
\hline $\mathrm{C}$ & $\ldots$ & $\cdots$ & + & $\cdots$ & $\cdots$ & $\cdots$ & $\cdots$ \\
\hline $\begin{array}{l}\text { NI } \\
\text { D }\end{array}$ & + & $\dddot{*}$ & $\begin{array}{l}+ \\
\ldots\end{array}$ & $\begin{array}{l}\cdots \\
\ldots\end{array}$ & $\begin{array}{l}\cdots \\
\ldots\end{array}$ & $\begin{array}{l}\cdots \\
\ldots\end{array}$ & $\begin{array}{l}\cdots \\
\ldots\end{array}$ \\
\hline $\mathrm{R}$ & $\ldots$ & + & + & $\ldots$ & $\ldots$ & $\ldots$ & $\ldots$ \\
\hline$S$ & + & $\cdots$ & $\cdots$ & + & $\cdots$ & $\cdots$ & $\ldots$ \\
\hline
\end{tabular}

In our earlier account we suggested that the rings now fixed in the heterozygous condition were of a kind normally floating in an outbreeding population. Seven interchanges is by no means unprecedented. Ten different interchanges were recorded in eleven interchange heterozygotes found among 933 individuals of the prosobranch mollusc Purpura lapillus (Staiger, 1955).

\section{SELECTION FOR HETEROZYGOSITY}

Spontaneous chromosome mutations, such as interchanges, occur less frequently than gene mutations. When they arise, they usually remain permanently floating in the population. They are rarely incorporated into the genetic systems of wild animal populations in the heterozygous condition as they have been in many plants, for example, Peonia californica. There appear to be two reasons for this :

Firstly, interchange hybrids, as a result of non-disjunction, may 
be semi-sterile and therefore subject to negative selection. This objection does not apply to the cockroach populations. The high frequency of multiple formation and their regular disjunction indicate high fertility. This is expected for, being under genetic control, both these chromosome characters are subject to selection (Rees, i955; Thompson, r956; Lawrence, r 958). Although selection will operate after the occurrence of interchanges, Periplaneta, like Enothera and Rhœo, is pre-adapted in its complete terminalisation. In addition, its meiosis is characterised by a pre-metaphase stretch which, so we believe, further facilitates disjunction (Lewis and John, I957).

Inbreeding a normally outbreeding species results in increasing homozygosity and consequent unbalance. Interchanges, by creating differential segments and by extending the linkage group, can preserve heterozygosity. In animals, where the sexes are separate, this change in the breeding system is less common and is a second reason why interchange heterozygosity is rarely established.

This objection again does not apply to the present populations. All are inbred. $P$. americana is not native to this country and we have never encountered populations on the surface (Lewis and John, 1957). The wild coal mine populations are therefore comparable with isolated communities of a species at the limit of its range : communities similar to those in Peonia and Enothera where interchange hybridity has been established (Darlington, I956). Of course, in the case of $P$. americana in this country the range cannot extend.

The laboratory cultures are also inbred because they are continually decreased in size. Indeed, the higher coefficient of interchange heterozygosity would suggest that they are even more inbred than the wild populations. This is probably true for they are usually depleted in every generation and closer inbreeding will follow such a decrease in population size.

The populations from the two localities within the coal mine at Treharris were different. Although these are separated by less than a few hundred yards this probably means that they are spatially isolated. The only roadway connecting the populations is permanently illuminated and in constant use ; these factors probably discourage migration.

It was suggested that five of the seven interchanges in the Treharris material had occurred in three chromosomes. This means that there is a higher probability of producing individuals heterozygous with respect of these chromosomes in the same way as multiple alleles facilitate genic heterozygosity. It has been shown in rye that selection does not favour heterozygotes indiscriminately but rather favours heterozygosity in particular chromosomes (Rees, I956). If this is the case in $P$. americana it would appear that heterozygosity in these three chromosomes is favoured in particular for there is no reason to believe that interchanges arise more often in some chromosomes than in others. 
The pachytene associations observed in other populations are morphologically similar to those in Treharris. Crosses are now in progress to determine whether these are dissimilar interchanges or similar interchanges of dissimilar ancestry.

These investigations on $P$. americana show how inbreeding can result in the establishment of structural hybridity even in a diœcious species. They also show that different populations can evolve independently in the same direction as have different sections of the genus Enothera. Indeed our unpublished investigations on cockroaches of different genera suggest that this may apply to larger taxonomic groups.

On the other hand, unrelated groups often have propensities for chromosome change in different directions, for interchange heterozygosity is not the only way of maintaining balance on inbreeding. In Locusta migratoria we would suppose that supernumerary chromosomes serve this purpose because they have been found in all the inbred laboratory cultures examined (Rees, 1954). This may be true also of Cimex species where the frequency of supernumerary " $\mathrm{X}$ " chromosomes is different in culture than in nature (Darlington, I939). In this connection it is significant that in Enothera the addition of different extra chromosomes can render a particular lethal diploid combination viable (Catcheside, 1936). In Drosophila on the other hand inversions have been exploited. Perhaps the direction of change is determined by pre-adaptation. On this basis the establishment of interchange heterozygosity, for example, is unlikely in a species like Allium fistulosum which has proximally localised chiasmata and no terminalisation.

Although there are many ways in which the chromosome mechanism can resist changes in the breeding system most of the permanent diploid hybrids in nature are interchange heterozygotes. This is probably because only interchanges can join determinants on different chromosomes together in the same linkage group.

\section{SUMMARY}

I. Four wild populations and six laboratory cultures of $P$. americana are described which have a high frequency of interchange heterozygotes. All these populations are inbred.

2. The multiples form and disjoin with a regularity expected to give a high fertility. It is suggested that $P$. americana is pre-adapted for the establishment of interchange heterozygosity in :

(i) Complete terminalisation, and

(ii) The presence of a pre-metaphase stretch at meiosis, both of which facilitate disjunction.

3. Interchange heterozygosity has been established independently in a number of populations. Interchanges arise infrequently and their establishment in the heterozygous condition must be due to selection. 


\section{Plate}

Fig. I,- Type 2 pachytene cross of four $\left(\mathrm{T}_{2}-\mathrm{I}\right.$, colchicine $6 \frac{1}{2} \mathrm{hr} . \quad \times 4000$.

Fig. 2.-Type 3 pachytene cross of four (TC-I I, untreated. $\times 4000$ ).

Fig. 3.-Type 4 pachytene cross of four $\left(\mathrm{T}_{2-5}\right.$, colchicine $\left.7 \mathrm{hr} . \quad \times 4000\right)$.

Fig. 4.-Induced "diakinesis" in a homozygote (R-4, colchicine I hr. $\times$ I250).

FIG. 5.-Pachytene in a ring-of-four heterozygote (S-6, colchicine $\left.\mathrm{I} \frac{1}{2} \mathrm{hr}, \times 2000\right)$.

Fig. 6.-Induced "diakinesis" in an individual heterozygous for two rings-of-four (M-7, colchicine, $3 \frac{1}{2} \mathrm{hr} . \times 2000$ ).

Fig. 7.-Induced "diakinesis" in a ring-of-six heterozygote (M-6, colchicine $4 \mathrm{hr} . \times 2000)$.

Fig. 8.--Induced "diakinesis" in an individual heterozygous for a ring-of-six and a ringof-four (M-5, colchicine $3 \mathrm{hr}$. $\times 2000)$.

Fig. 9.-First metaphase in a chain four heterozygote. Chain in disjunctional orientation (TC-I I, untreated. $\times 4000$ ). 


$$
\begin{aligned}
& f \quad \because \because 08 \%
\end{aligned}
$$

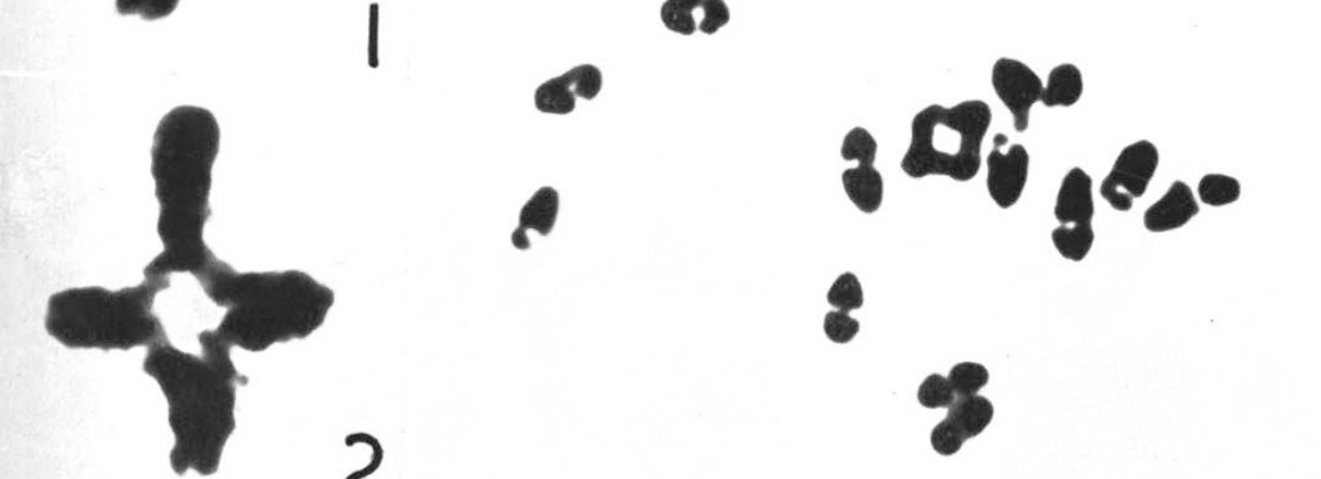

$$
\begin{aligned}
& 10: 0^{\circ} 0^{\circ} \\
& 0_{0}^{0} 00_{0}^{\circ} \div \\
& 488_{1}, 1+\text { ते }_{13}
\end{aligned}
$$


4. It can be correlated with a change in the breeding system from outbreeding to inbreeding as has been shown in Campanula and inferred in Enothera.

5. To account for the number and morphology of the multiples, seven interchanges are indicated in the Treharris material, five of these in three homologous pairs. This indicates that selection favours heterozygosity for these chromosomes.

6. It is suggested that related groups may show a propensity for chromosome change in the same direction determined, perhaps, by pre-adaptation.

7. Of the chromosome mechanisms which can resist changes in the breeding system interchange heterozygosity is favoured because this alone extends the linkage group to cover more than one chromosome.

Acknow:ledgments.-We are indebted to Prof. C. D. Darlington for criticism and suggestions and to Dr Alan Durrant, Dept. of Agricultural Botany, Aberystwyth, for valuable advice in the preparation of this paper.

\section{REFERENCES}

CATCHEside, D. G. 1936. Origin, nature and breeding behaviour of Enothera lamarckiana trisomics. 7. Genet., 33, I-23.

DARLINGTON, C. D. I939. The genetical and mechanical properties of the sex chromosomes. V. Cimex and the Heteroptera. 7. Genet., 39, I I I-137.

Darlington, C. D. 1956. Chromosome Botany. Allen and Unwin, London.

DARLington, C. D., AND LA CouR, L. F. 1950. Hybridity selection in Campanula. Heredity, 4, 21 7-248.

JOHN, B., AND LEWIS, K. R. I957. Studies on Periplaneta americana I. Experimental analysis of male meiosis. Heredity, $11, \mathrm{I}-9$.

LAWRENCE, C. W. 1958. Genotypic control of chromosome behaviour in rye. VI. Selection for disjunction frequency. Heredity, 12, 127-131.

LEWIS, K. R., AND JOHN, B. 1957. Studies on Periplaneta americana II. Interchange heterozygosity in isolated populations. Heredity, II, I I-22.

MAKINo, s. 1939. On the tetraploid spermatocytes produced by irradiation in Podisma mikado (Acrididae). Jap. 7. Genet., I5, 80-82.

REES, H. I955. Genotypic control of chromosome behaviour in rye. I. The inbred lines. Heredity, 9, 93- I 6 .

REES, H., AND JAmieson, A. I954. A supernumerary chromosome in Locusta. Nature, I73, 43 .

suomalainen, E. 1946. Die Chromosomenverhältnisse in der Spermatogenese einiger Blattarien. Ann. Acad. Sci. Fenn., A, 4, Io, I-6o.

StAiger, H. I955. Reziproke Translokationen in Natürlichenpopulationen von Purpura lapillus (Prosobranchia). Chromosoma, 7, $18 \mathrm{I}-197$.

тномpson, J. в. 1956. Genotypic control of chromosome behaviour in rye. II. Disjunction at meiosis in interchange heterozygotes. Heredity, IO, 99-1 o8.

THOMPSON, J. B., AND REES, H. 1956. Selection for heterozygotes during inbreeding. Nature, ${ }^{177}, 385-386$. 